\title{
Chronotype, general health and quality of sleep in a population of Spanish nurses
}

\section{Cronotipo, salud general y calidad del sueño en una población de enfermeros españoles Cronótipo, saúde geral e qualidade do sono em uma população de enfermeiros espanhóis}

How to cite this article:

Debbia F, Medina-Valverde MJ, García-Arcos A, Garrido-Gutiérrez A, Rodríguez-Borrego MA, López-Soto PJ. Chronotype, general health and quality of sleep in a population of Spanish nurses. Rev Esc Enferm USP. 2021;55:e03752. https://doi.org/10.1590/S1980-220X2020010903752

\author{
Fabio Debbia ${ }^{1,2}$ \\ Maria José Medina-Valverde ${ }^{1,3}$ \\ Aurora García-Arcos ${ }^{1,3}$ \\ Antonio Garrido-Gutiérrez ${ }^{1}$ \\ Maria Aurora Rodríguez-Borrego $\mathbf{1}^{1,3,4}$ \\ Pablo Jesús López-Soto ${ }^{1,3,4}$ \\ ${ }^{1}$ Instituto Maimónides de Investigación \\ Biomédica de Córdoba, Department \\ of Nursing, Córdoba, Spain. \\ ${ }^{2}$ Università Degli Studi di Ferrara, Ferrara, Italy. \\ ${ }^{3}$ Hospital Universitario Reina \\ Sofía, Córdoba, Spain. \\ ${ }^{4}$ Universidad de Córdoba, Córdoba, Spain.
}

\begin{abstract}
Objective: The aim of this study was to investigate the association between chronotype, general health status and sleep quality in a sample of Spanish nurses. Method: An observational study assessing morningness-eveningness predisposition, general health status and quality of sleep was conducted between January and April 2018. Univariate and multivariate analyses were performed. A linear regression model was carried out to determine the influence of the variables on the morningness-eveningness type. Results: Morning-type was associated with aging $(\beta=0.249, \mathrm{p}=0.005)$, being married $(\beta=3.970$, $p=0.033)$, and with a self-assessed low daily sleepiness $(\beta=-0.311, p=0.152)$. Good quality of sleep was moderately correlated with high values of general health $(r=0.337)$ and perceived quality of life $(\mathrm{r}=0.426)$. Conclusion: Anomalies of the circadian rhythm together with the features of shift workers may play an important role in predicting self-assessed general health status or the quality of sleep in nurses.
\end{abstract}

\section{DESCRIPTORS}

General Health; Sleep; Nurses; Occupational Health.
Corresponding author: Pablo Jesús López-Soto Department of Nursing, Instituto Maimónides de Investigación Biomédica de Córdoba Avda. Menéndez Pidal s/n. 14004 - Córdoba, Spain pablo.lopez@imibic.org 


\section{INTRODUCTION}

Most life forms have adapted to the planet through evolution by generating internal circadian rhythms, 24-hour patterns regulating behaviour, organs, and cells, which align their biological functions with the regular, predictable environmental patterns to optimise function and health ${ }^{(1)}$. The importance of circadian phases has been known for a long time and it is now clear they both play a fundamental role in human health and are endogenous in nature, since they have been shown to persist even in the absence of external environmental signs ${ }^{(2)}$. However, it has also been demonstrated that exogenous factors, such as exposure to electric light, may lead to alterations in the circadian clock $^{(3)}$. Hence, measurements of these rhythms are influenced by both endogenous and exogenous factors, and for a valid evaluation of their individual differences it is of primary importance to discriminate between these two sets of factors ${ }^{(4)}$.

Over the past few years, increased interest in an individual's circadian phase has emerged, especially after the research by Horne and Östberg into morningness and eveningness. In these studies, using a self-assessment questionnaire, they assessed for the first time individual differences in the time of day people preferred to carry out various activities. This led them to develop a theory which classified participants as: definitely morning type (DM), moderately morning type (MM), intermediate type (IT), moderately evening type (ME), and definitely evening type $(\mathrm{DE})^{(5)}$. This instrument, known as the Horne-Östberg Morningness-Eveningness Questionnaire (MEQ), is a 19-item test. Individual chronotypes (also called entrained phases) show great variability and tend to fall between the two extremes (known also as "larks" and "owls") in a normal distribution ${ }^{(6)}$. Many studies have reported how these differences preferences for the time of day affect an individual's behavior, especially when performing tasks or carrying out assignments. The studies focused on measuring vigilance and response inhibition, with DM and MM type groups showing linear decreasing inhibition performance only in the evening session, while they retained greater accuracy and stability in the morning session ${ }^{(7)}$. In contrast, the ME and DE groups showed a similar but inverse response to that of the DM and MM groups. Morning types (M-types) and Evening types (E-types), categories, which are often defined in the literature as subgroups DM-MM and ME-DE, also showed significant differences when tested on the optimal time of day for dealing with a persuasive message. It has been demonstrated that each group pays greater attention to, and acts on a persuasive message with a different attitude, at their respective optimal times of day, compared to those tested at their non-optimal time of day ${ }^{(8)}$. A more recent study examining possible relationships between chronotype, gender and disturbances that could negatively impact general health, found that being E-type might impact general physical or mental health, sleep, school results and achievements, especially in the young and in women ${ }^{(9)}$. Similar patterns have appeared in cross-sectional studies on academic achievement in students, with M-type individuals exhibiting better academic performance than E-type, although these results might be influenced by the generally early schedules of most universities ${ }^{(10)}$.

However, in the case of nursing professionals, since patients require 24-hour attention, they are required to work in shifts, which exposes them to a desynchronisation of their internal circadian clocks, leading to cumulative sleep debt, which is a characteristic deficiency in shiftworkers ${ }^{(11)}$. While many studies have focused on the correlation between shift work disorder (SWD) and the general health status of nurses, relatively few have attempted to associate circadian rhythms with health and sleep ${ }^{(12)}$. More recently, a quantitative systematic review by our research group summarised the existing evidence about chronotype and gender in the development of sleep and mood problems in nursing professionals, highlighting the fact that E-type female nurses seem to suffer more from problems of insomnia, sleepiness, fatigue, and anxiety, which in turn impacts patient safety and the quality of their clinical practice ${ }^{(13)}$.

This study looked into the association between chronotype, general health status and sleep quality among Spanish nursing professionals, through a cross-sectional study. This was a preliminary study to obtain useful data to help define a broader study on the same topic in the near future.

\section{METHOD}

\section{Study DESIGN}

A descriptive observational study was performed, based on a survey conducted between January and April 2018 at two different hospitals in Southern Spain (one private hospital and one Level-3 public hospital). The total number of nursing professionals, randomly selected through a Random Number Table previously provided by hospitals accounts, was 106 ( $\mathrm{n}=16$ in the private hospital and 90 in the public hospital). However, 14 of these declined to participate (response rate: $86.8 \%$ ), and so, in total, 92 nurses were interviewed.

\section{Population}

For the study period, the number of nursing professionals in the reference hospitals was 193 (private hospital) and 1,676 (public hospital). The percentage of women was $76.1 \%$ (private hospital) and $83.7 \%$ (public). The general mean age of the nursing professionals was 41 years old in the private hospital and 47.5 in the public one.

The current scientific literature estimates that $10.0 \%-$ $44.3 \%$ of shiftwork nursing professionals are affected by some form of vigilance and attention deficit. Specifically, in a Japanese study a prevalence of $24.4 \%$ was detected in a sample of 1,202 nurses ${ }^{(14)}$. Consequently, we considered that a sample size of randomly selected ninety subjects would suffice to make estimations with a $95 \%$ confidence and a precision of $+/-10$ percent units, in a population percentage considered to be around $25 \%$. We also anticipated a replacement rate of $20 \%$. 


\section{SELECTION CRITERIA}

In this study, inclusion criteria were as follows: being an adult ( $\geq 18$ years of age), having experience working in the same location for at least four months, and accepting and signing the consent form.

\section{Data collection}

The variables analysed in the present study were grouped into the following categories: (1) sociodemographic variables: age, gender, marital status, presence of children, number of children, distance of home from workplace (in minutes), work experience (in years) and work experience at the current location (in years), unit type (medical, surgical, multipurpose), full-time or part-time schedule, shiftwork schedule (regular shift, rotating shift, mixed), number of patients per nurse, and accidents occurring in the ward during the last year (yes/no); (2) chronotype variables: the Spanish version of MEQ was used to assess chronotype, with score ranges from 16 to 86 , with subgroups E-type (16-41), I-type (42-58; for these subjects, there is no defined chronotype) and M-type (59-86); (3) General Health variables: (i) the Spanish version of the General Health Questionnaire-28 (GHQ28) was used to assess general health. This is composed of four sub-scales which examine somatic symptoms, anxiety-insomnia, social dysfunction and depression, and, with a cut-off score $\geq 6$, has been validated against the GHQ60 ${ }^{(15)}$; (ii) the Spanish version of the 36-item Short Form Health Survey (SF36) was used to assess perceived quality of life in the respondents. The total score was $0-100$, with the categories of "excellent" (85-100), "very good" (62-84), "good” (26-61), "normal" (13-25), and "bad”"(16); (4) quality of sleep variables: (i) the Spanish version of the Pittsburgh Sleep Quality Index (PSQI) was used to assess quality of sleep. The questionnaire examines seven different dimensions and for each dimension a score from 0 (no difficulty) to 3 (severe difficulty) is assigned, giving a total of $0-21$. In line with previous reports, we associated sleep difficulty with a score $\geq 6^{(17)}$; (ii) The Spanish version of the Epworth Sleepiness Scale (ESS) was used to assess sleepiness, fatigue, attention and cognitive functions. Based on the final score, the scale produced three different classifications of low daily sleepiness or no sleepiness (0-6), medium daily sleepiness (7-8), and abnormal sleepiness $(\geq 9)^{(18)}$.

The data were collected through self-administered validated questionnaires designed by trained professionals. Following the established methodology, we recorded every single variable we considered could have an impact on the main issue (chronotype, general health and quality of sleep). Finally, a statistical analysis was performed.

\section{DATA ANALYSIS AND TREATMENT}

The data analysis was performed using IBM SPSS Statistics, Version 25 (IBM Corp, Armonk, NY, USA). For a descriptive analysis of the quantitative variables, the means and standard deviations (SD) were calculated, while for the qualitative variables we used counts (n) and proportions (\%). When the quantitative variables were analyzed, the Kolmogorov-Smirnov test was performed to verify the adherence of the data to the normal distribution. The correlation between the different variables of interest (MEQ, GHQ28, SF36, PSQI and ESS) was analyzed by means of the Pearson or Spearman Correlation coefficient, according to the normality or not of the variable. The reliability of the questionnaires used was evaluated by means of the Cronbach Alpha coefficient. A linear regression model was performed to determine the influence of the variables on the MEQ type, both as a quantitative and as a qualitative variable (M-type, I-type and E-type). Variables with a $\mathrm{p} \geq 0.15$ were not considered in the model. In addition, the coefficient $\beta$ and 95\%CI were calculated. All the comparisons driven by hypotheses were bilateral, and statistical significance was established at $\mathrm{p}<0.05$.

\section{ETHICAL ASPECTS}

This study was conducted following the ethical standards of the Helsinki Declaration (2013 review), and after formal approval by the Ethics Committee for Research (Register Number 3518, Act Number 274). All the data was processed confidentially and with no third party unauthorised access, in accordance with Organic Law 3/2018, dated December 5 , on the Protection of Personal Data and Guarantees of Digital Rights, a realignment of the Spanish law to meet Regulation (EU) 2016/679 of the European Parliament and Council, dated 27 April 2016, regarding the processing of personal data and the free movement of such data (GDPR).

\section{RESULTS}

The final sample size consisted of 92 nurses, aged 26-62 years old (mean 49.27 years of age; $\mathrm{SD} \pm 9.93$ ). 19.6\% (18 individuals) were men and $80.4 \%$ were women (74 individuals). Most of the sample $(68.5 \%, \mathrm{n}=63)$ were married at the time of the survey, while $22.8 \%(\mathrm{n}=21)$ were single, $5.4 \%(\mathrm{n}=5)$ were divorced and 3.3\% ( $n=3)$ were widowed. More than three-quarters of the sample $(79.3 \%, \mathrm{n}=73)$ had children, with a mean number of $1.6(\mathrm{SD} \pm 0.8)$ for the whole sample.

Regarding the workplace, $71.9 \%$ of nurses $(n=66)$ travelled less than thirty minutes to get to the hospital, $23.9 \%(n=22)$ commuted for $30-60$ minutes, while only $1.1 \%(n=1)$ had a journey of more than one hour. The mean commuting time was 20.4 minutes $(\mathrm{SD} \pm 11.3)$. Most of the sample $(68.5 \%$, $\mathrm{n}=63$ ) had professional experience of over twenty years, $19.6 \%$ ( $\mathrm{n}=18$ ) had 10-19 years' experience, and 10.9\% ( $\mathrm{n}=10)$ had $<10$ years'experience, with an overall mean of 24.2 years of experience $(\mathrm{SD} \pm 10.31$ ), compared to the mean for experience in their current workplace of 11.30 years $(\mathrm{SD} \pm 8.9)$. The work schedule was full-time for $84.8 \%$ of the sample ( $n=78)$, and part-time for $14.1 \%(n=13) .29 .3 \%(n=27)$ of the nurses worked on a regular shift, while $56.5 \%(\mathrm{n}=52)$ had a rotating shift and 3.3\% (n=3) had a mixed shift. Multipurpose units were the most common work setting for the nurses in our sample (42.4\% of respondents, $\mathrm{n}=39)$, with medical units for $30.4 \%(n=28)$, and surgical units for $20.7 \%(n=19)$. Almost one third of the sample took care of over ten patients during their daily routine $(30.4 \%, \mathrm{n}=28), 17.4 \%(\mathrm{n}=16)$ looked after $5-10$ patients and $16.3 \%(\mathrm{n}=15)$ cared for $<5$ patients. Lastly, $29.3 \%$ of the nurses $(n=27)$ reported accidents occurring during their shifts over the last year. Table 1 shows these variables in working situations. 
Table 1 - Characteristics of working situations in the study sample - Córdoba, Andalusia, Spain, 2018.

\begin{tabular}{|c|c|c|c|}
\hline Variable & Category & $\mathbf{N}$ & $\%$ \\
\hline \multirow[t]{4}{*}{ Commuting time in minutes (mean $20.4 \pm 11.3$ ) } & $<30$ & 66 & 71.7 \\
\hline & $31-59$ & 22 & 23.9 \\
\hline & $>60$ & 1 & 1.1 \\
\hline & (lost) & (3) & (3.3) \\
\hline \multirow[t]{4}{*}{ Professional experience in years (mean $24.2 \pm 10.31)$} & $0-9$ & 10 & 10.9 \\
\hline & $10-10$ & 18 & 19.6 \\
\hline & $>20$ & 63 & 68.5 \\
\hline & (lost) & $(1)$ & $(1.1)$ \\
\hline \multirow[t]{3}{*}{ Work schedule } & Full-time & 78 & 84.8 \\
\hline & Part-time & 13 & 14.1 \\
\hline & (lost) & (1) & $(1.1)$ \\
\hline \multirow[t]{4}{*}{ Shift } & Regular & 27 & 29.3 \\
\hline & Rotating & 52 & 56.5 \\
\hline & Mixed & 3 & 3.3 \\
\hline & $($ lost $)$ & $(10)$ & $(10.9)$ \\
\hline \multirow[t]{4}{*}{ Work setting } & Medical & 28 & 30.4 \\
\hline & Surgical & 19 & 20.7 \\
\hline & Multipurpose & 39 & 42.4 \\
\hline & (lost) & (6) & $(6.5)$ \\
\hline \multirow[t]{4}{*}{ Patient ratio } & $>10$ & 28 & 30.4 \\
\hline & $5-10$ & 16 & 17.4 \\
\hline & $<5$ & 15 & 16.3 \\
\hline & (lost) & (33) & $(35.9)$ \\
\hline \multirow[t]{3}{*}{ Accidents during last shift } & Negative & 53 & 57.6 \\
\hline & Positive & 27 & 29.3 \\
\hline & (lost) & (12) & (13) \\
\hline
\end{tabular}

The Cronbach's alpha of the MEQ, PSQI and GHQ28 questionnaires were above 0.7 , which was considered an acceptable value $(0.71,0.76$ and 0.92 , respectively). In the cases of SF-36 and EES, the values were below 0.5 (0.35 and 0.43 ; respectively)

The MEQ results showed a mean of 53.29 (SD \pm 7.43 ), with no significant differences between females and males, and with an almost normal distribution (median $=54.00)$ of types/classes: E-type 5.4\% ( $\mathrm{n}=5)$, I-type 68.5\% ( $\mathrm{n}=63)$, and M-type $26.1 \%(\mathrm{n}=24)$. The PSQI mean was $7.0(\mathrm{SD} \pm 3.5)$, with, again, no significant differences between females and males, and with $59.8 \%$ of the sample $(\mathrm{n}=55)$ showing some disturbances in their sleep quality time (PSQI $\geq 6$ ). The only non-parametric variable was GHQ28 (mean 3.39, $\mathrm{SD} \pm 5.05$, median 1.00), with $22.8 \%(\mathrm{n}=21)$ of the sample reporting some kind of alteration in their general health perception (GHQ28 $\geq 6$ ). The ESS reported an overall mean of 6.6 $(\mathrm{SD} \pm 3.9)$, with $21.7 \%$ of respondents $(\mathrm{n}=20)$ reporting abnormal sleepiness $(\mathrm{ESS} \geq 9), 20.7 \%(\mathrm{n}=19)$ medium sleepiness (ESS 7-8) and 57.6\% $(\mathrm{n}=53)$ low or absent sleepiness (ESS $\leq 6)$. Lastly, the SF36 variable showed a mean of 13.0 $(\mathrm{SD} \pm 3.9)$ and a normal distribution (median $=13.0)$, with no significant differences between females and males. In this survey, $3.3 \%$ of the sample $(n=3)$ reported a low quality of life, with $21.7 \%$ of nurses judging theirs as "normal" $(n=20)$, $42.4 \%$ as "good" ( $n=39)$ and $29.3 \%$ as "very good" $(n=27)$. Part of these descriptive results, with correlations among the variables, are presented in Table 2 .

Table 2 - Mean, Standard Deviation and Number for MEQ, PSQI, GHQ28, ESS and SF36, and Spearman's Rho between single variables - Córdoba, Andalusia, Spain, 2018.

\begin{tabular}{|c|c|c|c|c|c|c|c|}
\hline & \multirow{2}{*}{ Mean } & \multirow{2}{*}{ SD } & \multirow{2}{*}{$\mathbf{N}$} & MEQ & PSQI & GHQ28 & ESS \\
\hline & & & & Coef. (p- value) & Coef. (p-value) & Coef. (p-value) & Coef. (p-value) \\
\hline MEQ & 53.29 & 7.43 & 92 & $1.000()$. & & & \\
\hline PSQI & 7.02 & 3.52 & 91 & $-0.045(0.674)$ & $1.000()$. & & \\
\hline
\end{tabular}




\begin{tabular}{|c|c|c|c|c|c|c|c|}
\hline & \multirow{2}{*}{ Mean } & \multirow{2}{*}{ SD } & \multirow{2}{*}{$\mathbf{N}$} & MEQ & PSQI & GHQ28 & ESS \\
\hline & & & & Coef. (p- value) & Coef. (p-value) & Coef. (p-value) & Coef. (p-value) \\
\hline GHQ28 & 3.39 & 5.05 & 92 & $-0.108(0.306)$ & $0.337^{* *}(0.001)$ & $1.000()$. & \\
\hline ESS & 6.68 & 3.98 & 92 & $-0.212 *(0.042)$ & $0.154(0.145)$ & $0.285^{* *}(0.006)$ & $1.000()$. \\
\hline SF36 & 13.08 & 3.95 & 89 & $-0.114(0.286)$ & $0.426^{* *}(<0.001)$ & $0.611^{* *}(<0.001)$ & $0.176(0.099)$ \\
\hline
\end{tabular}

Note: ${ }^{* *}$ Correlation is significant at at level of $0.01 ;{ }^{*}$ Correlation is significant at a level of 0.05 .

In order to detect possible associations, we also verified the MEQ independent association (as a quantitative variable) with all the variables included in the survey, discovering significant associations among several of them. The MEQ results were positively correlated with age (Pearson's correlation $r=0.349, p=0.005)$, as well as with years of work experience (Pearson's $r$ 0.346, $p=0.001$ ), and were negatively correlated with ESS (Spearman's Rho -0.212, $\mathrm{p}=0.042$ ). In addition, two different Student's t-tests indicated that the sample had no homogeneity of variances between the MEQ mean of married nurses and single nurses (difference in means, MD -4.205, 95\%CI -7.633/-0.788, $\mathrm{p}=0.017$ ) or between the mean of nurses with children and nurses without children (MD -6.119, 95\%CI -10.818/-1.420, $p=0.013)$. The only significant correlation that emerged between singular scales was with the ESS, with a Pearson's $\mathrm{r}$ of $-0.212(\mathrm{p}=0.042)$.

The linear logistic regression model (Table 3) showed that a higher MEQ score was positively associate with being older $(\beta=0.249 \pm 0.086,95 \% \mathrm{CI} 0.077-0.420, p<0.01)$ and being married $(\beta=3.970 \pm 1.823,95 \% \mathrm{CI} 0.323-7.617$, $\mathrm{p}=0.03)$. In contrast, a negative association emerged for the ESS score, with a higher score associated with a lower one for the MEQ, although it narrowly failed to reach statistical significance $(\beta=-0.311 \pm 0.214$, $95 \% \mathrm{CI}-0.740-0.118, \mathrm{p}=0.15)$. This lack of statistical significance might have been due to the relatively small size of the study population.

Table 3 - Linear regression model: $\beta$ and 95\% Confidence Intervals for independent variables associated with MEQ. [Adjusted $\left.\mathrm{R}^{2}=0.176\right]$ - Córdoba, Andalusia, Spain, 2018.

\begin{tabular}{lccc}
\hline Variable & $\beta( \pm \mathrm{SD})$ & $\mathbf{9 5} \% \mathrm{Cl}$ & $\mathrm{p}$-value \\
\hline Age (per year) & $0.249( \pm 0.086)$ & $0.077-0.420$ & $<0.01$ \\
Being married & $3.970( \pm 1.823)$ & $0.323-7.617$ & 0.03 \\
Epworth Sleepiness Scale & $-0.311( \pm 0.214)$ & $-0.740-0.118$ & 0.15 \\
\hline
\end{tabular}

As regards gender, although there were no significant differences, higher PSQI mean (MD -0.72, 95\%CI -2.56$1.12, \mathrm{p}=0.440)$, ESS mean (MD -0.72, 95\%CI -2.56-1.12, $\mathrm{p}=0.181)$, and SF36 mean (MD -1.35, 95\%CI $-3.41-0.71$, $\mathrm{p}=0.197$ ) levels were found in women. These findings have been summarised in Table 4 .

Table 4 - Differences of means and Standard Deviation for women and men in MEQ, PSQI, GHQ28, ESS and SF36 - Córdoba, Andalusia, Spain, 2018.

\begin{tabular}{lccccc}
\hline & $\begin{array}{c}\text { Female } \\
\text { Mean }( \pm \text { SD })\end{array}$ & $\begin{array}{c}\text { Male } \\
\text { Mean }( \pm \text { SD) }\end{array}$ & MD & 95\%Cl & p-value \\
\hline MEQ & $52.9( \pm 7.7)$ & $54.5( \pm 6.0)$ & 1.56 & $-2.32-5.46$ & 0.425 \\
PSQI & $7.1( \pm 3.3)$ & $6.4( \pm 4.2)$ & -0.72 & $-2.56-1.12$ & 0.440 \\
GHQ28 & $3.5( \pm 5.1)$ & $2.6( \pm 4.6)$ & -0.97 & $-3.61-1.67$ & 0.468 \\
ESS & $6.9( \pm 4.2)$ & $5.5( \pm 2.3)$ & -1.40 & $-3.47-0.66$ & 0.181 \\
SF36 & $13.3( \pm 3.7)$ & $12.0( \pm 4.5)$ & -1.35 & $-3.41-0.71$ & 0.197 \\
\hline
\end{tabular}

\section{DISCUSSION}

It is normal for nurses to be on call 24 hours a day to care for patients in many different settings and environments. The consequences for their physical and psychological wellbeing of shift management (managing the turnover between rotating, day-only and night-only shifts, etc.) and lengths of shifts (12, 9, 8 or 6 hours) have been studied frequently ${ }^{(19)}$. The common point which emerges from all these studies is that anomalies in the circadian rhythm, together with the characteristics of shift workers may have a direct influence 
on nurses' health. This current cross-sectional study highlights the possible associations between chronotype, general health and quality of sleep in a cohort of Spanish nurses, an area of research not previously addressed.

In this previous research, models showed a positive association of the M-type phenotype with being older, in line with other series ${ }^{(20)}$, despite being applied to a cohort of 1,020 high school students. Similar findings of MEQ scores increasing with age were also reported in another cohort of 2,526 adults, where younger participants were more likely to be DE-type, and less likely to be M-type, compared to older participants ${ }^{(21)}$. In another study, the chronotype was assessed using a different scale, the Munich ChronoType Questionnaire (MCTQ), in a very large population $(n=55,000)^{(22)}$. This study reported that children generally have earlier chronotypes, which progressively become later during development, reaching a maximum in this "lateness" at around the age of 20 . From this age onwards, they observed that chronotypes then become earlier again, with a late increase in the MEQ score also being detected.

Marital status was also an important predictor of chronotype in the current study, with married participants much more likely to be M-type. This contrasts with a previous study, where being married or living with a partner resulted in an association with an eveningness chronotype ${ }^{(23)}$. This variation in results illustrates the need to investigate this issue more deeply.

Even though the inverse association between MEQ scores and ESS scores narrowly failed to reach statistical significance in the current study, similar results were found in Italy ${ }^{(24)}$. The Italian study had a similar predominance of women (68\% in a cohort of 324 Italian nurses) to our study, and the E-type individuals were associated with a difficulty in overcoming sleepiness $(\beta=0.23, p<0.02)$, even though the data were obtained using different instruments. The influence of chronotype on sleep quality was also found in medical students ${ }^{(25)}$, with a lower risk of poor sleep quality in M-type and I-type compared to the E-type. This is a relevant aspect for patient safety, as indicated in a recent article on 401 Italian midwives, which reported that the younger ones with less working experience, who carried out shift work and belonged to an Intermediate chronotype, seemed to be at higher risk of potential medication error ${ }^{(26)}$.

The reliability of our questionnaires was acceptable in all cases, except for SF-36 and EES. Specifically, several data were missing on the SF-36 scale (in "functioning of social role"), and the same occurred with the item 'watching TV' of the EES questionnaire. Cronbach's alpha is a reliability statistic which is less robust when there is missing data. Nevertheless, similar studies in nursing professional have shown acceptable values for EES and SF36 $(0,74-0,76)^{(27)}$.

There was no significant difference in MD between males and females, and so this was not included in the logistic regression model; however, the eveningness chronotype was associated with being female (MD with homogeneity of variances $=1.56,95 \% \mathrm{CI}-2.32-5.46, \mathrm{p}=0.425)$. However, this was still an interesting preliminary correlation to report, as the association could become significant with a larger sample. Similarly, other studies found that gender predicted a significant change in the Diurnal Type Scale (DTS), with women obtaining higher scores in the morning chronotype ${ }^{(28)}$. On the other hand, the role of gender and its correlation with chronotype has also been shown to present different trends. One study with 1253 female nurses and midwives ${ }^{(29)}$ found poor rates of sleep in the E-type, three-shift rotation workers and workers with leg motor restlessness. Furthermore, another recent study found that female nurses experienced more sleep problems and digestive and cardiovascular problems than male nurses, while, in contrast, women had higher scores on the General Health Questionnaire (which the current study also found, though this was not significant: MD -0.97 , 95\%CI -3.61-1.67, $\mathrm{p}=0.468)$ and had less shift-time satisfaction ${ }^{(23)}$. In conclusion, gender seems to be more relevant with more variables, and there may be a correlation with being female, although this hypothesis did not reach statistical significance.

Work-related variables such as the type of shifts or the occurrence of adverse events had no statistical relevance on the analyses performed. In this context, a recent review shows that the occurrence of medication errors can be influenced by stress, fatigue, nurse staffing ratio, workload and night shifts ${ }^{(30)}$. Also, night or rotating-shift work are associated with melatonin disruption (specifically, in urine melatonin levels). Melatonin is multi-tasking molecule which is commonly known as a reliable marker of the circadian system. It would therefore be desirable to extend the scope of this research into the influence of chronotype on occupational health and patient safety.

We should also take into account the fact that the nature of the cross-sectional design did not allow us to make causal inferences; hence, longitudinal studies would be required to confirm any cause-effect relationships. Also, in our study we could not evaluate any gender effect, as most of the sample were women, as usually occurs in studies on nurses and midwives ${ }^{(26)}$.

\section{CONCLUSION}

Anomalies in circadian rhythms, together with the features of shift work, seems to play an important role in predicting self-assessed general health status or quality of sleep in nurses, as well as morningness-eveningness predisposition. These outcomes could be influenced by sociodemographic features, such as age, gender or marital status. A lower mean MEQ score was associated in our sample with being female, although not at a statistically significant level, and the same could be stated for the higher PSQI, ESS and SF36 means. The findings of this study imply that hospital administrators should rely on scientific data to provide sufficient resources, psycho-social support and shift-work schedules in order to prevent sleep problems or general health disorders in nurses. Due to the small sample size, it was not possible to assess gender difference in our study. Considering previous contradictory findings, more research on the subject is needed in order to establish precise correlations and eventual causation. 


\section{RESUMEN}

Objetivo: Este estudio tuvo como objetivo investigar la asociación entre el cronotipo, el estado general de salud y la calidad del sueño en una muestra de enfermeras españolas. Método: Desde enero a abril de 2018, se realizó un estudio observacional para evaluar la predisposición matutina-vespertina, el estado de salud general y la calidad del sueño. Se realizaron análisis univariante y multivariante. Se efectuó un modelo de regresión lineal para determinar la influencia de las variables en el tipo matutino-vespertino. Resultados: El tipo matutino se asoció con el envejecimiento $(\beta=0,249 ; \mathrm{p}=0,005)$, estar casado $(\beta=3,970 ; \mathrm{p}=0,033)$ y con un bajo nivel de somnolencia diaria autoevaluada $(\beta=-0,311 ; p=0,152)$. La buena calidad del sueño se correlacionó moderadamente con valores altos de salud general $(r=0,337)$ y de calidad de vida percibida $(r=0,426)$. Conclusión: Las anomalías del ritmo circadiano junto con las características de los trabajadores por turnos pueden desempeñar un papel importante en la predicción del estado de salud general autoevaluado o la calidad del sueño de las enfermeras.

\section{DESCRIPTORES}

Estado de Salud; Sueño; Enfermeras y Enfermeros; Salud Laboral.

\section{RESUMO}

Objetivo: O objetivo deste estudo foi investigar a associação entre cronótipo, estado geral de saúde e qualidade do sono em uma amostra de enfermeiras espanholas. Método: Foi realizado um estudo observacional entre janeiro e abril de 2018 que avaliou a predisposição matutina-vespertina, o estado geral de saúde e a qualidade do sono. Foram realizadas análises univariadas e multivariadas. Um modelo de regressão linear foi realizado para determinar a influência das variáveis sobre o tipo matutino-vespertino. Resultados: O tipo matinal foi associado ao envelhecimento $(\beta=0,249, p=0,005)$, ser casado $(\beta=3,970, p=0,033)$ e com baixa sonolência diária autoavaliada $(\beta=-0,311, p=0,152)$. Boa qualidade de sono foi moderadamente correlacionada com altos valores de saúde geral $(\mathrm{r}=0,337)$ e qualidade de vida percebida $(\mathrm{r}=0,426)$. Conclusão: Anomalias do ritmo circadiano em conjunto com as características dos trabalhadores em turnos podem desempenhar um papel importante na previsão do estado geral de saúde autoavaliado ou da qualidade do sono em enfermeiras.

\section{DESCRITORES}

Nível de Saúde; Sono; Enfermeiras e Enfermeiros; Saúde do Trabalhador.

\section{REFERENCES}

1. Voigt RM, Forsyth CB, Green SJ, Engen PA, Keshavarzian A. Circadian rhythm and the gut microbiome. Int Rev Neurobiol. 2016;131:193-205. https://doi.org/10.1016/bs.irn.2016.07.002

2. Roenneberg T, Merrow M. The Circadian clock and human health. Curr Biol. 2016;26(10):R432-43. https://doi.org/10.1016/j cub.2016.04.011

3. Wright KP Jr, McHill AW, Birks BR, Griffin BR, Rusterholz T, Chinoy ED. Entrainment of the human circadian clock to the natural light-dark cycle. Curr Biol. 2013;23(16):1554-8. https://doi.org/10.1016/j.cub.2013.06.039

4. Kerkhof GA. Inter-individual differences in the human circadian system: a review. Biol Psychol. 1985;20(2):83-112. https://doi.org/10.1016/0301-0511(85)90019-5

5. Horne JA, Östberg O. A self-assessment questionnaire to determine morningness-eveningness in human circadian rhythms. Int J Chronobiol [Intenet]. 1976 [cited 2020 Jan 20];4(2):97-110. Available from: https://www.ncbi.nlm.nih.gov/pubmed/1027738

6. Roenneberg T, Wirz-Justice A, Merrow M. Life between clocks: daily temporal patterns of human chronotypes. J Biol Rhythms. 2003;18(1):80-90. https://doi.org/10.1177/0748730402239679

7. Lara T, Madrid JA, Correa Á. The vigilance decrement in executive function is attenuated when individual chronotypes perform at their optimal time of day. PLoS One. 2014;9(2):e88820. https://doi.org/10.1371/journal.pone.0088820

8. Martin PY, Martin R. Morningness-eveningness orientation and attitude change: evidence for greater systematic processing and attitude change at optimal time-of-day. Pers Individ Dif. 2013;54(5):551-6. https://doi.org/10.1016/j.paid.2012.10.031

9. Fabbian F, Zucchi B, De Giorgi A, Tiseo R, Boari B, Salmi R, et al. Chronotype, gender and general health. Chronobiol Int. 2016;33(7):863-82. https://doi.org/10.1080/07420528.2016.1176927

10. Valladares M, Ramírez-Tagle R, Muñoz MA, Obregón AM. Individual differences in chronotypes associated with academic performance among Chilean University students. Chronobiol Int. 2018;35(4):578-83. https://doi.org/10.1080/07420528.2017.1413385

11. Pallesen S, Nordhus IH, Omvik S, Sivertsen B, Tell GS, Bjorvatn B. Prevalence and risk factors of subjective sleepiness in the general adult population. Sleep. 2007;30(5):619-24. https://doi.org/10.1093/sleep/30.5.619

12. Li M, Huang JT, Tan Y, Yang BP, Tang ZY. Shift work and risk of stroke: a meta-analysis. Int J Cardiol. 2016;214:370-3. https://doi.org/10.1016/j.ijcard.2016.03.052

13. López-Soto PJ, Fabbian F, Cappadona R, Zucchi B, Manfredini F, García-Arcos A, et al. Chronotype, nursing activity, and gender: a systematic review. J Adv Nurs. 2019;75(4):734-48. https://doi.org/10.1111/jan.13876

14. Asaoka S, Aritake S, Komada Y, Ozaki A, Odagiri Y, Inoue S, et al. Factors associated with shift work disorder in nurses working with rapid-rotation schedules in Japan: the nurses' sleep health project. Chronobiol Int. 2013;30(4):628-36. https://doi.org/10.3109/0742052 8.2012 .762010

15. Lobo A, Pérez-Echeverría MJ, Artal J. Validity of the scaled version of the General Health Questionnaire (GHQ-28) in a Spanish population. Psychol Med. 1986;16(1):135-40. https://doi.org/10.1017/S0033291700002579

16. Alonso J, Prieto L, Antó JM. [The Spanish version of the SF-36 Health Survey (the SF-36 health questionnaire): an instrument for measuring clinical results]. Med Clin (Barc) [Internet]. 1995 [cited 2020 Mar 31];104(20):771-6. Spanish. Available from: https://www.ncbi.nlm.nih. gov/pubmed/7783470 
17. Royuela A, Macía Fernández JA. Propiedades clinimetricas de la versión castellana del cuestionario de Pittsburgh. Vigilia-Sueno [Internet]. 1997 [cited 2020 Apr 1];9(2):81-94. Available from: https://www.researchgate.net/publication/258705863_Propiedades_clinimetricas_de_ la_version_castellana_del_cuestionario_de_Pittsburgh

18. Chiner E, Arriero JM, Signes-Costa J, Marco J, Fuentes I. [Validation of the Spanish version of the Epworth Sleepiness Scale in patients with a sleep apnea syndrome]. Arch Bronconeumol. 1999;35(9):422-7. Spanish. https://doi.org/10.1016/S0300-2896(15)30037-5

19. Scott LD, Arslanian-Engoren C, Engoren MC. Association of sleep and fatigue with decision regret among critical care nurses. Am J Crit Care. 2014;23(1):13-23. https://doi.org/10.4037/ajcc2014191

20. Milić J, Kvolik A, Ivković M, Cikes AB, Labak I, Benšic M, et al. Are there differences in students' school success, biorhythm, and daytime sleepiness depending on their school starting times? Coll Antropol [Intenet]. 2014 [cited 2020 Apr 1];38(3):889-94. Available from: https://www.ncbi.nlm.nih.gov/pubmed/25420370

21. Paine SJ, Gander PH, Travier N. The epidemiology of morningness/eveningness: influence of age, gender, ethnicity, and socioeconomic factors in adults (30-49 years). J Biol Rhythms. 2006;21(1):68-76. https://doi.org/10.1177/0748730405283154

22. Roenneberg T, Kuehnle T, Juda M, Kantermann T, Allebrandt K, Gordijn M, et al. Epidemiology of the human circadian clock. Sleep Med Rev. 2007;11(6):429-38. https://doi.org/10.1016/j.smrv.2007.07.005

23. Korompeli A, Muurlink O, Tzavara C, Velonakis E, Lemonidou C, Sourtzi P. Influence of shiftwork on Greek nursing personnel. Saf Health Work, 2014;5(2):73-79. 2014.03.003 https://doi.org/10.1016/j.shaw.2014.03.003

24. Costa G, Anelli MM, Castellini G, Fustinoni S, Neri L. Stress and sleep in nurses employed in " $3 \times 8$ " and " $2 \times 12$ " fast rotating shift schedules. Chronobiol Int. 2014;31(10):1169-78. https://doi.org/10.3109/07420528.2014.957309

25. Sun J, Chen M, Cai W, Wang Z, Wu S, Sun X, et al. Chronotype: implications for sleep quality in medical students. Chronobiol Int. 2019;36(8):1115-23. https://doi.org/10.1080/07420528.2019.1619181

26. Cappadona R, Di Simone E, De Giorgi A, Boari B, Di Muzio M, Greco P, et al. Individual circadian preference, shift work, and risk of medication errors: A cross-sectional web survey among Italian midwives. Int J Environ Res Public Health. 2020;17(16):E5810. https://doi.org/10.3390/ijerph17165810

27. Waage S, Pallesen S, Moen BE, Magerøy N, Flo E, Di Milia L, et al. Predictors of shift work disorder among nurses: a longitudinal study. Sleep Med. 2014;15(12):1449-55. https://doi.org/10.1016/j.sleep.2014.07.014

28. Vedaa Ø, Bjorvatn B, Magerøy N, Thun E, Pallesen S. Longitudinal predictors of changes in the morningness-eveningness personality among Norwegian nurses. Pers Individ Dif. 2013;55(2):152-6. https://doi.org/10.1016/j.paid.2013.02.016

29. Uekata S, Kato C, Nagaura Y, Eto H, Kondo H. The impact of rotating work schedules, chronotype, and restless legs syndrome/WillisEkbom disease on sleep quality among female hospital nurses and midwives: A cross-sectional survey. Int J Nurs Stud. 2019;95:103-12. https://doi.org/10.1016/j.ijnurstu.2019.04.013

30. Di Muzio M, Dionisi S, Di Simone E, Cianfrocca C, Di Muzio F, Fabbian F, et al. Can nurses' shift work jeopardize the patient safety? A systematic review. Eur Rev Med Pharmacol Sci. 2019;23(10):4507-19. https://doi.org/10.26355/eurrev_201905_17963 